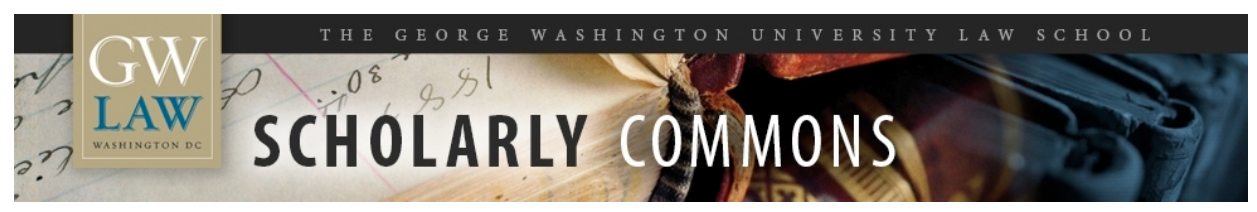

\title{
Risky Business: Should the FDA Pay Attention to Pharmaceutical Prices?
}

\author{
David A. Hyman \\ William E. Kovacic \\ George Washington University Law School, wkovacic@law.gwu.edu
}

Follow this and additional works at: https://scholarship.law.gwu.edu/faculty_publications

Part of the Law Commons

\section{Recommended Citation}

Hyman, David A. and Kovacic, William E., Risky Business: Should the FDA Pay Attention to Pharmaceutical Prices? (May 18, 2017). GWU Law School Public Law Research Paper No. 2017-37; GWU Legal Studies Research Paper No. 2017-37. Available at SSRN: https://ssrn.com/abstract=2970683

This Article is brought to you for free and open access by the Faculty Scholarship at Scholarly Commons. It has been accepted for inclusion in GW Law Faculty Publications \& Other Works by an authorized administrator of Scholarly Commons. For more information, please contact spagel@law.gwu.edu. 


\title{
Risky Business: \\ Should the FDA Pay Attention to Pharmaceutical Prices?
}

\author{
David A. Hyman \\ Georgetown University School of Law \\ William E. Kovacic \\ George Washington University School of Law
}

Draft May, 2017

This paper can be downloaded without charge from the Social Science Research Network electronic library at

https://ssrn.com/abstract $=2970683$ 


\title{
Risky Business: Should The FDA Pay Attention to Pharmaceutical Prices?
}

\author{
David A. Hyman \& William E. Kovacic ${ }^{*}$
}

\begin{abstract}
People are angry about drug prices. What role, if any, should the FDA play in addressing this issue? Historically, the FDA's answer has been "not our problem." As the quality and safety agency, the FDA has repeatedly refused to get involved in drug pricing matters, even when its actions (and inactions) have contributed to the problem. We examine the circumstances under which the FDA should pay attention to pharmaceutical prices, and discuss the implications of it doing so.
\end{abstract}

${ }^{*}$ Hyman is Professor of Law, Georgetown University Law Center. Email: dah137@georgetown.edu. Kovacic is Global Competition Professor of Law and Policy, George Washington Law School. Email: wkovacic@law.gwu.edu. 


\section{Introduction}

The dream is always the same. ${ }^{1}$ Congress should enact sweeping laws that turn everything over to technocratic regulators, giving them carte blanche to do whatever serves the public interest. These disinterested experts will apply the delegated authority wisely and effectively, delivering truth, justice, and prosperity - and will do so without the rent-seeking, log-rolling and earmarks that are associated with getting the political branches (i.e., Congress and the President) involved.

Of course, that's often not the way things turn out. Market failure is real, but so is government failure. Regulators are not always neutral - and most of them are not actually technocratic experts. ${ }^{2}$ Stated differently, expertise informs their judgments, but so does politics (both large "P" and small "p"). Regulators can pick sides - and use their sweeping regulatory authority to make life miserable for those who are on the outs. Regulators can also screw up. Sometimes regulators don't have the requisite information to understand (let alone fix) the problem. Sometimes the tools regulators have are the wrong ones for the job (i.e., "if the only tool you have is a hammer. ..") Regulators can also be too risk-averse - or not risk-averse enough. They can have tunnel vision - or they can seek to use their power to leverage outcomes that lie far outside the scope of their properly delegated authority. ${ }^{3}$ Regulators can be too cozy with the industries they regulate, or not cozy enough. And so on.

The FDA has avoided many (but certainly not all) of these problems. Any agency with as broad a portfolio as the FDA is certain to run into difficulties. For the FDA, the flash point has turned on the trade-off between innovation and safety. Advocates for each of these (laudable) goals are quick to condemn decisions that seem to favor the other goal. In the words of the recently departed FDA Commissioner:

The balancing of risks and benefits is fundamental to FDA's regulatory role. And it is always a challenge. We joke that FDA is viewed as having only two approval speeds: too fast and too slow. We are perceived as too quick to approve a drug or device when a significant safety issue is identified in the post-market context once the product is in widespread use. On the other hand, we were too slow in approving when a drug that has undergone a lengthy development and review is finally approved and provides a real therapeutic benefit to patients. The task for FDA's scientist is to strike the right regulatory balance. ${ }^{4}$

More concretely, those who prioritize innovation criticize the FDA for being too risk averse in approving drugs, because the agency (rightly) anticipates being pilloried for false positives (i.e., approving drugs it should not), but knows it will receive much less criticism for false negatives (i.e., delaying or denying approval of drugs that it should have). These critics (who tend to be drawn from the right side of the political spectrum) believe the result is delayed and/or denied approvals, resulting in tens of thousands of invisible (but no less real) deaths. Conversely, those who prioritize safety believe that the FDA has been too willing to approve ineffective and risky

\footnotetext{
${ }^{1}$ See Risky Business (1983), where the first line in the movie "the dream is always the same."

${ }^{2}$ For starters, going to law school doesn't make you a technocratic expert. But, by all means, feel free to go to law school.

${ }^{3}$ William E. Kovacic \& David A. Hyman, Regulatory Leveraging: Problem or Solution? 23 Geo. Mason. L. Rev. 1163 (2016).

4 Margaret A. Hamburg, Lessons Learned: How the FDA Matters, National Press Club Newsmakers Luncheon, Mar. 27, 2015, at http://www.fda.gov/NewsEvents/Speeches/ucm440315.htm
} 
drugs, in part because of Congressional pressure to lower the standards for drug approval, compounded by the corrupting influence of user fees. These critics (who tend to be drawn from the left side of the political spectrum) believe the result is tens of thousands of visible deaths and considerable disability. Both sides point to specific examples supporting their respective positions, and are quick to discount the concerns raised by their opponents.

These battles have been going on for decades, with both sides arguing about where, at any given point in time, the FDA falls on the drug approval Goldilocks spectrum (i.e., is the agency acting too fast, too slow, or just right?). And, these issues seem likely to remain policy perennials, if the recent debates over the $21^{\text {st }}$ Century Cures Act and Right to Try laws are any indication. ${ }^{5}$

Notwithstanding these disputes, if you asked a random member of the general public or of Congress to identify the single most important issue in the drug policy space, our bet is that "cost" would be by far the most popular response. And, there is no shortage of examples that help explain that response - whether it is Martin Shkreli (Daraprim); Mylan (the Epi-pen); or the spiral of increases in the sticker price for a wide array of brand-name drugs.

So where is the FDA when it comes to drug costs? When asked, FDA personnel are quick to explain that drug pricing is not their problem:

Ask any US Food and Drug Administration (FDA) official how the agency can help lower prescription drug prices and you're likely to hear the same answer: Drug pricing is not under FDA's purview. And sure enough, FDA doesn't dip its toe into the pricing bog while deciding whether to approve or reject a new drug, and it also doesn't negotiate with pharmaceutical companies over how to price drugs. ${ }^{6}$

This response captures the FDA's long-standing position. The FDA's organization, culture, and behavior reflects its self-understanding that it is the safety and efficacy czar. No drug gets onto the market without FDA permission - but once the drug is approved, the FDA has no interest in the price point at which it changes hands. Periodic attempts to get the FDA to respond to drug pricing "problems," have been deflected, deflated, or simply ignored.

As we detail below, the FDA's decades-long honeymoon on this issue is almost certainly over. We anticipate the FDA will come under increasing pressure to address drug pricing. When that happens, will no longer be whether the FDA should pay attention to drug prices. Instead, it will about but how and when the FDA should do so.

In this essay, we sketch out the logic of having the FDA pay at least some attention to drug prices, and identify the (limited) circumstances under which drug pricing should figure into FDA

\footnotetext{
5 Jonathan J. Darrow, et al, Practical, Legal, and Ethical Issues in Expanded Access to Investigational Drugs 372 New Engl. J. Med. 279 (2015).

${ }^{6}$ See, e.g., Zachary Brennan, What FDA Can and Can't Do to Help Lower Drug Prices, RAPS.org, Nov. 18 , 2015, at http://raps.org/Regulatory-Focus/News/2015/11/18/23635/What-FDA-Can-and-Can't-Do-to-Help-LowerRising-Drug-Prices; Jeremy A. Greene, Gerard Anderson and Joshua M. Sharfstein, Role of the FDA in Affordability of Off-Patent Pharmaceuticals, 315 JAMA 461 (2016); Michael Hiltzik, The FDA can single-handedly reduce drug price-gouging. Why is it waiting?, L.A. Times, Jan. 5, 2016, at http://www.latimes.com/business/hiltzik/la-fi-mh-thefda-can-single-handedly-stop-20160105-column.html.
} 
decision-making (Part II). Then we discuss the implications of letting the drug pricing genie loose within the corridors of the FDA, and various related issues (Part III). Part IV concludes.

\section{Why The FDA Should Pay Attention to Drug Prices}

Prices communicate information. Why wouldn't an agency charged with regulating a market pay attention to pricing information about the goods being sold in that market - particularly when the agency controls access to the market? Of course, the FDA does not regulate price directly - but it does not follow that the agency should simply ignore prices, even if it would prefer to focus on the technocratic "thumbs up" or "thumbs down" drug approval decision.

As everyone who knows anything about the FDA understands, the agency's statutory mandate focuses on safety and efficacy. But, there are at least two distinct reasons why the FDA should pay at least some attention to drug prices. First, at least for generics, drug pricing can communicate information about the FDA's performance. Generic drug entry is an immensely powerful tool with which to lower drug prices. But, if generics are not being approved in a timely fashion, drug prices may remain at elevated levels, even though the underlying drug is long since off-patent.

Bureaucracies can easily become complacent about backlogs, since they experience them only as an ever-growing pile of paperwork accumulating in the agency's inbox. After all, it's is only paperwork. The paperwork pile was there yesterday, and it will be there tomorrow. Maybe drug companies have to wait longer for their drug approvals than they would like, but there are $\mathrm{n}+1$ holes in the dike that the FDA is guarding, and only $n$ plugs with which to fill them. As long as every drug company is treated the same, no company has a valid complaint. ${ }^{7}$

But, if the FDA starts paying attention to drug pricing, the human cost of the agency's approval backlog suddenly becomes immediate and concrete. Agency leadership are forced to recognize the significant harms that result when the FDA has a backlog of generic drug approval requests. Indeed, drug prices provide an immediate feedback loop on the real-world consequences of the FDA failing to clear the backlog. The FDA can also use pricing information to identify and prioritize applications that should get bumped to the front of the queue for processing. And, it can use the pricing information to lobby Congress for more personnel: "we need more money to process generic drug applications. The level and trends in drug pricing shows that we aren't blowing smoke."

Pricing information also helps cast light on the consequences of other aspects of the FDA's operations. Consider the Unapproved Drugs Initiative ("UDI"), launched by the FDA in $2006 .{ }^{8}$ The UDI was an attempt to deal with the fact that various drugs were being sold without FDA approval. Consistent with the UDI, the FDA warned companies that specific drugs were unapproved, and invited them to test them. Firms that tested their drugs received a period of market exclusivity. From the FDA's perspective, the UDI was a straightforward strategy to push unapproved drugs off the market, using a carrot (market exclusivity for firms that tested their drugs) and a stick (enforcement actions against firms that failed to test their drugs). Best of all, the costs of market exclusivity were externalized to consumers, rather than treated as an on-budget

\footnotetext{
${ }^{7}$ This attitude explains why the Veterans Administration was so complacent about the waiting lists it was employing to ration access to care - and why it circumvented or gamed Congressional attempts to get a handle on the problem. 8 See FDA, Unapproved Drugs Initiative, http://www.fda.gov/Drugs/GuidanceComplianceRegulatoryInformation/EnforcementActivitiesbyFDA/SelectedEnfo rcementActionsonUnapprovedDrugs/ucm118990.htm
} 
expense for the agency. Predictably enough, multiple companies conducted some quick and dirty testing, and then used the resulting market exclusivity as a license to jack up prices. The most aggressive/creative companies also sought to achieve orphan drug status for their products, further increasing the period of market exclusivity.

The pricing consequences were clear. To pick but one example, the price of colchicine, used for the treatment of gout, went from 10 cents a tablet to $\$ 5$ dollars. ${ }^{9}$ Unsurprisingly, these increases in cost affected utilization. One study found "a reduction in colchicine initiation and an increase in patient spending... [but no] association with improvements in avoidance of potentially dangerous co-prescriptions."10

Of course, the pricing consequences of the UDI were not limited to colchicine. The price of $17 \mathrm{OHP}$, used to prevent premature births, went from $\$ 15$ per injection to $\$ 1,440$. The price of extended release guaifenesin, used in cough syrup, went up by $700 \% .{ }^{11}$ Other examples are not hard to find.

If the focus is solely on the number of unapproved drugs on the market, the UDI would have to be scored an unmixed success. But, if the focus includes information on drug pricing and access to care the case looks quite different. Indeed, if the FDA had focused, it is far from clear that it should have gone forward with the UDI. At a minimum, greater consideration should have been given to the likely pricing consequences of granting an extended period of market exclusivity for cheap drugs that had been on the market for decades.

The FDA's response to criticisms of the UDI also reveals its mindset. In a letter published in the New England Journal of Medicine, in response to an article about the colchicine debacle, the FDA Commissioner and a staff member wrote the following:

Because URL Pharma was the first to submit clinical trial data and be granted approval for oral colchicine, federal law required that the company be given marketing exclusivity for the indication of acute gout for 3 years and for the indication of familial Mediterranean fever for 7 years. Congress wrote these laws to encourage innovation, although such regulations sometimes have a broader sweep. The FDA is required to implement the laws as written and has no authority to regulate drug prices. Manufacturers could seek approval for colchicine for chronic gout; no marketing exclusivity exists for this indication.

The FDA is focused on ensuring that all drugs are held to the same safety, efficacy, and quality standards. The FDA noted 117 non-overdose deaths (some recent) that were associated with oral colchicine (with 51\% involving an interaction between colchicine and clarithromycin). Clinical trials of Colcrys showed that lower doses were as effective as higher doses and produced fewer side effects. As

\footnotetext{
9 Allan S. Brett, Spotlight on Colchicine: The Colcrys Controversy, NEJM Journal Watch (June 10, 2010), http://www.jwatch.org/jw201006100000001/2010/06/10/spotlight-colchicine-colcrys-controversy. See also Aaron S. Kesselheim and Daniel H. Solomon, Incentives for Drug Development - The Curious Case of Colchicine 362 New Engl. J. Med. 2045 (2010).

${ }^{10}$ Aaron S. Kesselheim et al, Reductions in Use of Colchicine after FDA Enforcement of Market Exclusivity in a Commercially Insured Population, 30 J. Gen. Intern. Med. 1633 (2015).

${ }^{11}$ Ryan M. Mott, Colchicine, Guaifenesin, and the Constitutionality of FDA Market Exclusivity for Approval Pioneers, unpublished manuscript (2012), available at https://works.bepress.com/ryan mott/1/.
} 
a result of the FDA's review and approval of Colcrys, this information must now be included in the drug's label. ${ }^{12}$

Stated more concisely, "it's not us; it's the law. And don't bother us about pricing, since that's not our problem either."

But Congress and the general public were entirely unpersuaded by these arguments. For colchicine, there was "universal outrage" about the price increases. ${ }^{13}$ For 17-OHP, the outcry in Congress and the news media was so loud that the FDA backed down, and allowed compounding pharmacies to continue to manufacture the product. These reactions point to the second reason for the FDA to pay attention to drug prices. People expect the FDA to pay attention to drug prices because it is the Food and Drug Agency. When a public agency visibly fails to do what Congress and the general public expect it to do, bad things happen to agency leadership - and sometimes, to the agency itself.

For both of these reasons, we believe the time is ripe for the FDA to start paying attention to drug prices. If the agency doesn't address this issue on its own, it may well find the issue rammed down its throat.

\section{Discussion}

\section{A. Gaming the FDA Approval Process: Citizen Petitions and REMS}

So far, we have focused on the pricing consequences of the UDI, and on the FDA's failure to approve generic drugs on a timely basis. But, other aspects of the FDA's operations create the opportunity for similar adverse impacts on pricing. Consider citizen petitions. In theory, citizen petitions provide a way for external constituencies to trigger FDA scrutiny of drugs that the agency would otherwise overlook or assign a lower priority. But citizen petitions can also be used to deter generic entry, as Mylan did with the Epi-pen, ${ }^{14}$ and ViroPharma did with Vancomycin. ${ }^{15}$

FDA's Risk Evaluation and Mitigation Strategies ("REMS") raise many of the same concerns as citizen petitions. REMS are intended to be used to mitigate the risks associated with unrestricted use of specific drugs. ${ }^{16}$ But REMS can also be used to delay generic entry. ${ }^{17}$ And in 2014 , fully $40 \%$ of newly approved drugs had a REMS. ${ }^{18}$ One study estimated that delays in

12 Janet Woodcock and Sarah Okada, Incentives for Drug Development - The Curious Case of Colchicine, 363 New Engl. J. Med 1484 (2010).

${ }^{13}$ John D. FitzGerald, Good Intentions, Unintended Consequences, and Unrealized Benefits, 30 J. Gen. Intern. Med. 1581 (2015).

${ }^{14}$ Michael A. Carrier \& Carl J. Minniti, Citizen Petitions: Long, Late-Filed, and At-Last Denied, 66 American University Law Review 305 (2016).

$\begin{array}{llllllll}15 & \text { FTC } & \text { v. } & \text { Shire } & \text { Viropharma, } & \text { Feb. } & 7, & 2017,\end{array}$ https:/www.ftc.gov/system/files/documents/cases/viropharma file-stamped redacted complaint.pdf

16 FDA Basics Webinar: A Brief Overview of Risk Evaluation and Mitigation Strategies (REMS), at http:/www.fda.gov/AboutFDA/Transparency/Basics/ucm325201.htm. See also FDA, A Brief Overview of Risk Evaluation \& Mitigation $\quad$ Strategies $\quad$ (REMS), http:/www.fda.gov/downloads/AboutFDA/Transparency/Basics/UCM328784.pdf.

17 FTC Amicus Brief: Improper Use of Restricted Drug Distribution Programs May Impede Generic Competition, Mar. 12, 2013, at https://www.ftc.gov/news-events/press-releases/2013/03/ftc-amicus-brief-improperuse-restricted-drug-distribution; Henry Butler, REMS-Restricted Drug Distribution Programs and the Antitrust Economics of Refusals to Deal with Potential Generic Competitors, 67 Florida L. Rev. 979 (2015).

18 Alex Brill, Lost Prescription Drug Savings from Use of REMS Programs to Delay Generic Market Entry (2014), at http://www.gphaonline.org/media/cms/REMS Studyfinal July2014.pdf. 
generic entry attributable to REMS cause Americans to pay an extra $\$ 5.4$ billion per year. ${ }^{19}$ If that estimate is correct, branded drug companies are likely to view REMS as a briar patch they want to be thrown into, rather than a real constraint on their ability to market their products.

As these examples indicate, the pricing problems associated with FDA action/inaction are not limited to UDIs and the agency's failure to approve generic drugs on a timely basis. As our discussion of citizen petitions and REMS indicate, multiple aspects of the FDA's operations can have unintended adverse consequences on drug pricing. Unless the FDA is paying attention to the issue, it will find it more difficult to detect such (mis)conduct, and track changes in the tactics that are being employed to game the FDA approval process. Even if the FDA partners with the FTC to address anti-competitive behavior, it still needs to regularly scrutinize its own operations to ensure they are not being turned to anti-competitive ends.

\section{B. Risks of Unleashing the Pricing Genie Within the FDA}

The FDA has long thought of itself as the safety and efficacy agency. What are the likely consequences and risks of allowing or encouraging the FDA to pay attention to drug prices? The most obvious risk is that the FDA will decide it is in the price-setting business - or come under sufficient pressure that it starts doing so. This is likely to prove a particular problem for branded drugs, where high prices are primarily attributable to the mechanisms by which we pay for prescription drugs - rather than attributable to anything the FDA is or isn't doing. ${ }^{20}$

Of course, paying attention to price will require the FDA to hire personnel with the appropriate skill-set (i.e., economists and lawyers). Organizational issues (i.e., should those responsible for the pricing portfolio be integrated into the drug approval teams, or set up in their own bureau? Who gets the last word?) will need to be resolved. There are likely to be intra- and inter-agency conflicts that will need to be mediated. In prior work, we examined these issues, and pointed out the complexities of managing a multi-mission agency. ${ }^{21}$ Simply stated, how well or poorly these risks are handled will make a big difference in whether having the FDA pay attention to drug prices works out well or poorly.

\section{Intruder Alert!}

The most common objection to our proposal is based on statutory text. If the FDA is the safety and efficacy agency, doesn't it violate the statutory mandate for the FDA to pay attention to drug pricing? And, doesn't the absence of statutory provisions relating to drug pricing from the $21^{\text {st }}$ Century Cures Act indicate that Congress has no interest in allowing the FDA to pay attention to drug pricing?

We think both of these objections are overstated. For those who believe in a living constitution and free-wheeling policy-oriented theories of statutory interpretation, the absence of explicit Congressional authorization is a barely discernable speed bump on the way to the desired objective. For textualists and originalists, the absence of explicit statutory authorization implies the FDA may not consider drug pricing in deciding whether to approve or disapprove a drug. But,

${ }^{19}$ Id.

${ }^{20}$ Some might argue that the FDA can fix problems with the pricing of branded drugs by authorizing routine reimportation. We are skeptical that approach will fix the underlying problem, even leaving aside the potential health risks of routine reimportation.

${ }^{21}$ David A. Hyman \& William E. Kovacic, Why Who Does What Matters: Governmental Design and Agency Performance, 82 Geo. Wash. L. Rev. 1446 (2014); David A. Hyman \& William E. Kovacic, Competition Agencies with Complex Policy Portfolios: Divide or Conquer? Concurrences Article No. 50967 (2013); William E. Kovacic \& David A. Hyman, Competition Agency Design: What's On the Menu? 8 European Comp. J. 527 (2013). 
even if we adopt the strictest possible construction of the FDA's statutory authority, it does not follow that the agency may not consider drug pricing in setting the agenda for the drug approval/review process - let alone in evaluating the effect of handing out market exclusivity. Other drug companies might complain about queue-jumping, but there is no property right in a company's place in the queue. And, the knowledge that the FDA might opt for queue-jumping if prices for generics rise discourages incumbent drug companies from doing just that.

\section{What Is to Be Done?}

It is one thing to say that the FDA should pay attention to drug prices, and entirely another to have a theory about what constitutes a pricing problem - let alone what the agency should do once it finds a pricing problem. In this short essay, we do not address these problems in any detail, although we identify four obvious strategies. Part of the solution is for the FDA and FTC to work together more closely. Part of the solution is to harden the FDA's policies and procedures to make them harder to game. Part of the solution is to send a clear signal to pharmaceutical companies that anti-competitive behavior will not be tolerated. Finally, the FDA should also send a clear signal to Congress and the public that the agency can't fix everything that is dysfunctional about drug pricing. To the extent pricing problems are attributable to the way we have chosen to pay for pharmaceuticals, the FDA can do little or nothing to remedy that issue.

What about the UDI? As we have already suggested, viewed from a FDA-centric perspective, the UDI was a sensible and cost-effective way of getting manufacturers to conduct the necessary tests for safety and efficacy - making it possible for the FDA to focus its efforts on getting the remaining unapproved drugs off the market. But, from a broader perspective, the UDI was a deeply stupid bureaucratic response to what was, from all appearance, a non-problem. The FDA did not bear the cost of conducting the necessary tests, and it paid no attention to the pricing consequences of the market exclusivity it was handing out - but that did not make those costs any less real for the consumers that had to pay them. So what should the FDA have done? Sometimes leaving well enough alone is the optimal solution - particularly when the alternative is to make things worse. ${ }^{22}$

\section{Conclusion}

In our view, the FDA should pay attention to drug prices when the information imbedded in those prices is about the real-world consequences of the FDA's actions and inactions. In some instances, the information conveyed by drug prices in this space will motivate the FDA to change course and/or reallocate its priorities. Even if the FDA elects not to make changes, at least it will know the consequences of its actions/inactions.

What about pricing information that reflects larger market dynamics, such as supply disruptions, monopoly power, and differences in prices across countries? In our view, the FDA should pay attention to pricing information that signals supply disruptions; inform the FTC and DOJ about pricing that appears to be attributable to monopoly or oligopoly; and ignore disparities in pricing across countries. Of course, reasonable people will disagree on where exactly each of these lines should be drawn - and what the FDA should do once it starts paying attention to pricing.

${ }^{22}$ David A. Hyman, Rescue Without Law: An Empirical Perspective on the Duty to Rescue, 84 Tex. L. Rev. 653 (2006) ("When it comes to the duty to rescue, leaving well enough alone is likely to be sufficient unto the day.") 
Finally, regardless of where the line is drawn, everyone involved should understand that the FDA is not the "fix everything that's wrong with the drug market" agency. That way lies chaos. 